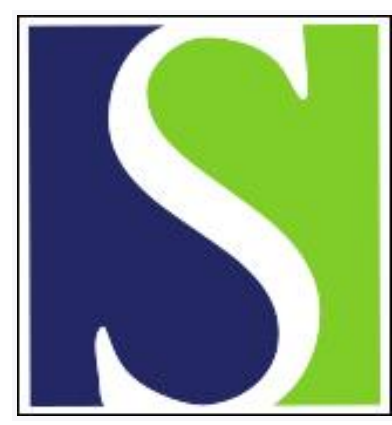

Scand J Work Environ Health 2001;27(6):422-425

https://doi.org/10.5271/sjweh.636

Issue date: Dec 2001

\title{
Airway allergy and worklife
}

by Malmberg $\mathrm{P}$, reporter

Affiliation: National Institute for Working Life, SE-171 84 Stockholm, Sweden. per.malmberg@niwl.se

Key terms: airway allergy; consensus report; healthy workplace; medical profession; scientific community; society; work-related asthma; working life; worklife

This article in PubMed: www.ncbi.nlm.nih.gov/pubmed/11800331

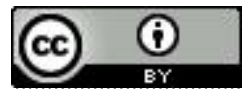




\section{Airway allergy and worklife}

European researchers, mostly members and officers of the European Respiratory Society, attended a workshop called "The High Prevalence of Airway Allergy - Implications for Work Life", in Brussels on 5-7 March 2000. The objective of the meeting was to delineate key issues and discuss central themes related to the topic on a collective level, instead of providing individual contributions, and this report was written as a result. It has been scrutinized and approved by the participants of the workshop, who are listed at the end of the report.

Since the report is meant for members of the medical profession and for decision makers in the European Union (EU), it has been written for a wide audience. For this purpose some information available in common textbooks is provided, although it was not discussed at the workshop, since it was common knowledge among the participants.

\section{Background}

Five to ten percent of the general population in Europe has asthma (1-5). This is a much higher figure than was the case a few decades ago. It is estimated that worldwide some 100-150 million persons have asthma.

Part of the explanation for the increase in asthma is a population shift in the immune system. As a result, the risk of becoming allergic to common substances in the air, typically proteins from mites, pollen or furred animals, has clearly increased. This increase in the disposition to develop allergic disease affects a large part of the population $(40-50 \%)$. The cause of this change is unknown, but it is has been attributed to factors in early childhood $(2,6,7)$.

Allergic disposition may result in asthma in childhood or in asthma with adult onset. Occupational exposure to both high- and low-molecular-weight agents may cause adult onset asthma, but in at least half of the cases with adult onset asthma it is not possible to identify a causal agent $(8,9)$.

Asthma is more common in teenagers than in adults, and, according to some estimates, more than $10 \%$ of young persons have asthma (1). The highest prevalence of asthma in the adult population is found in some countries of western Europe, where up to $10 \%$ of the population has this diagnosis. Asthma (but not asthmatic symptoms like wheezing) and allergy appear to be less common in eastern European countries (2). The prevalence of recognized allergies is, however, rising also in these countries (10).

A consequence of this change in the general population is that more people with asthma are now entering worklife. In addition, growing numbers of persons at work have an increased susceptibility to develop asthma from exposures to agents in the workplace.

\section{Work-related asthma - ten to fifteen percent of all asthma}

It is estimated that about $10 \%$ to $15 \%$ of all cases of adult asthma is associated with exposures at work (11, 12). These exposures may cause asthma or worsen preexisting asthma to such an extent that it affects work capacity.

Asthma is characterized by a chronic inflammation of the airways. The inflammation may or may not cause chronic symptoms, but it renders the airways hypersensitive to a variety of stimuli. The inflammation is worsened by exposure to agents to which the subject is sensitized (called allergens). Inhalation of very low doses of allergen may cause an asthma attack, but even when the amount of inhaled allergen is insufficient to cause an asthma attack, it may worsen the airway inflammation and hypersensitivity (13). Asthmatics often experience symptoms that are worse in the early morning hours. An asthma attack may be provoked by an allergen, but also by irritants or, for example, by exercise and cold air inhalation. Thus a person who experiences symptoms in the early morning or following a jogging tour on a day off work may not realize that the exposure causing the underlying airway inflammation may have occurred at work.

\section{Work related asthma - an underestimated problem?}

Although asthma is the dominating cause of occupational respiratory disease, the work relatedness of asthma is probably seriously underestimated. The data on attributable risk in the preceding section suggest that $10 \%$ or more of asthmatics, and thus almost $1 \%$ of the workforce in western European countries, has asthma that is caused or is significantly worsened by workplace 
exposures. Only a small fraction of these cases is recognized as having occupational asthma and therefore recorded in registers of the disease.

High-risk workplaces include those in which animals are present, those employing bakers and others handling enzymes, those where there is exposure to insects and mites, and those where certain chemical agents are used. The use of latex gloves for surgery may cause severe asthma. In addition, asthma is worsened by irritant exposures from dusts and fine particles, nitrogen dioxide, sulfur dioxide gas, cold air and exercise, strong scents, and environmental tobacco smoke. Common detergents and cleaning agents may also pose a threat. Examples of job titles with one or more such exposures are farmers and other workers in the food and feed industries, veterinarians, hairdressers, bakers, gardeners, laboratory technicians, medical staff and other health professionals, painters, furniture makers, solderers, welders, and workers in many chemical industries $(9,14-16)$. Indeed work-related asthma may occur in almost any sector of agriculture, industry, or service occupations.

Asthmatics working in places with a poor indoor climate may also be adversely affected by the workplace to an extent that is detrimental to health. Obvious examples of such environments are public places with exposure to environmental tobacco smoke (17) or to, for example, welding fumes. Another less obvious example is exposure to environmental allergens in school classrooms or other places where many persons are located in a confined indoor area. Many of the persons may carry, for example, pet allergen on clothing and thus contribute to undesirable allergen exposure (18).

The workshop members discussed possible mechanisms for the underdiagnosis of work-related asthma. It was suggested that many physicians lack awareness and knowledge of workplace exposures and thus do not pose appropriate questions to patients about possible relationships between work and asthma. Another potential factor for the underdiagnosis of work-related asthma is that patients with asthma, who experience worsening of symptoms at work, may suppress this information and increase the medication dose rather than consult an occupational health physician. Such a consultation may result in undesired relocation to other worktasks, and the workers may even fear that they may lose their jobs or end up with long-term wage losses.

\section{The healthy workplace}

It is therefore mandatory to institute measures that remove exposures at worklaces that cause occupational asthma or worsen asthma symptoms. The framework directive of the European Union (EU council directive 89/391 CEE) emphasizes the importance of preventive measures for the work environment. Otherwise a large proportion of the population may be unemployable in a large sector of the job market or will risk having to pay the price of ill health and increased medication.

It is not possible to reduce exposure at work to such an extent that even the most sensitive worker can perform all kinds of work. It is, however, important to reduce exposures in the workplace as far as possible in order to allow a majority of those with an allergic disposition or asthma to choose any job they want. The workshop members discussed different strategies for achieving this goal. Occupational exposure limits can only be used in situations in which reliable methods are available for measuring the agent and for which data on dose response are available and generally accepted. Such methods are being developed, and data on dose response are being collected for many high-molecularweight proteins that cause allergy. More work needs to be done, but there are several problems. Many protein allergens are insufficiently defined, and, although good methods exist for measuring some chemicals, new or modified chemicals are introduced every year. The rationale behind occupational exposure limits is challenged in a situation in which half the workforce is not affected at any exposure level. Even among the sensitive half of the workforce, there is a wide span of sensitivity, such that the most sensitive persons may react to an exposure that is several orders of magnitude lower than the exposure required to cause symptoms among less sensitive subjects.

It may not be possible to achieve a satisfactory environment for a veterinarian who is highly sensitized to animal allergens and who works in an animal clinic or for a baker sensitized to flour. Still there are several general measures that can be undertaken to improve the situation for most allergic workers. Adequate general ventilation and cleaning with nonallergenic cleaning agents reduce exposures. Textile materials in public places may need washing. Smoking in the workplace should not be allowed. Processes that lead to emissions of agents that cause or worsen asthma should, if possible, be contained or at least provided with local ventilation. Areas in which allergenic material is handled should be confined, and work should be organized to minimize exposure in other areas. These principles are not new, but they should be applied with vigor with the added objective of providing healthy workplaces for the large proportion of the workforce that has a disposition to develop allergy or is asthmatic.

\section{Vocational advice}

Vocational advice as discussed here refers to advice given to persons seeking employment in workplaces that 
may pose a problem for subjects with an allergic disposition or asthma that is not work-related. Persons who develop occupational asthma, due to, for example, isocyanate exposure, require rehabilitation that usually includes prompt removal from exposure to the offending agent.

General measures should improve the situation for most workers with allergy and, for that matter, also for nonallergic workers for whom exposure to irritants is reduced in the healthy workplace. As mentioned earlier, general measures may, however, not suffice for highly susceptible persons in some workplaces. For such people the choice of workplaces is restricted.

The restriction of workplaces poses questions of ethical and political implications. The workshop participants agreed that workers should have the choice and take the risk. Workers should base the choice upon adequate medical advice. The responsibility of the employer is to provide as safe a workplace as can be achieved. The alternative is that the employer may choose to reduce costs for workplace adjustments and possible productivity loss by selecting only workers with minimal risk. If so, a large proportion of the workforce may be barred from many highly attractive job opportunities. This issue has been brought to the medical profession with an ironic twist, since many physicians face a risk of developing allergy towards latex in, for example, examination gloves. Most physicians would probably emphasize the need to reduce exposure at the workplace rather than restrict access to the medical profession for those who may have a disposition to develop allergy.

A key issue is the assessment of risk for the development or worsening of asthma and other allergic diseases in a workplace. The situation would be different if it were possible to identify with great precision the persons who would develop occupational disease in a given workplace. In such a case, it would be ethically permissible to advise strongly against a person taking a job in specific branches and understandable if the employer refused such job applicants. However, in the experience of the participants of the workshop, all current data suggest that it is not possible with any degree of certainty to predict who will develop allergy on the basis of data obtained in a preemployment test. Even if workers are exposed to very strong allergens in the workplace, most workers with preemployment test data suggesting predisposition to develop allergy will not become sensitized. Conversely, even if the employer has been very restrictive, removing almost half of the workforce with any sign of predisposition to develop allergy, cases of occupational asthma would still occur. For some agents, notably the chemical sensitizers, there is no evidence that restrictive employment policies are effective, let alone justified, to prevent the occurrence of occupational asthma.
The medical advice to the job applicant should thus be influenced by the uncertainty of the prediction based on the history or test results. If an examination suggests an increased risk, this increased risk should result in advice to be especially careful to avoid or reduce harmful exposures rather than to seek employment in another branch. Indeed, it is rather late to provide such advice when the person is applying for a job. The ideal time for vocational advice is before vocational training, and indeed perhaps even earlier at school, before the decision to seek opportunities in a specific profession is made. In most countries advice regarding allergy risks does not seem to take place before vocational training begins.

\section{Society, the medical profession and the scientific community}

The workshop participants recognized, however, that, since employers often require and finance preemployment tests, they will ask to be informed of the outcome of the tests. It is probable that they will use this information for selecting their workforce as a primary method to reduce costs, at least in situations where there is an ample supply of job applicants.

Society must therefore be engaged in the promotion of healthy workplaces and in discouraging the use of selection instruments that have been proved inadequate by science. Employers who are clearly negligent regarding measures to achieve healthy workplaces should be penalized. Health promotion schemes should be amended at workplaces to include the specific needs of allergic persons.

The medical profession needs education in the potential work-relatedness of asthma and in the possibilities of adjusting workplaces to accommodate the growing number of asthmatics and persons with allergic disposition. Evidence-based consensus on vocational advice is needed for those with allergic disease or a disposition to develop allergy.

The scientific community should closely study the fate of young allergic persons entering worklife and develop better methods with which to assess workplace exposure in epidemiologic studies of asthma. A "sensor" system for detecting new cases of occupational asthma due to exposures to new agents, or in association with new work processes, should be established for the European community. Such a system could be devised as a database of the causes of occupational asthma that could be added to by all physicians. The database could be housed within a European organization and available over the net. Tests to monitor exposure and evaluate the health effects associated with occupational 
asthma should be standardized, for example, in accredited centers.

The workshop participants recognized the need to establish a dialogue at the European level between decision makers and the medical and scientific communities in order to promote healthy workplaces for all.

Participants: Josep M. Antó (Institut Municipal d'Investigació Mèdica, Universitat Pompeu Fabra, Barcelona, Spain), Sherwood Burge (Birmingham Heartlands Hospital, Birmingham, England), Paul Cullinan (National Heart \& Lung Institute, London, England), Frederic de Blay (University hospital, Strasbourg, France), Cinzia Di Pede (Department of Occupational Medicine (ISLL), Local Health Unit, Pisa, Italy), Dick Heederik, (Institute for Risk Assessment Sciences, Utrecht, The Netherlands), Antti Karjalainen (Finnish Institute of Occupational Health, Helsinki, Finland), Francine Kauffmann (INSERM, Villejuif Cedex, France), Per Malmberg (National Institute for Working Life, Stockholm, Sweden), Christina Mapp (Department of Clinical and Experimental Medicine, University of Ferrara, Ferrara, Italy), Henrik Nordman (Finnish Institute of Occupational Health, Helsinki, Finland), Ben Nemery (The Catholic University of Leuven, Leuven, Belgium), Katja Radon (Institute for Occupational and Environmental Medicine, Ludwig-Maximilians-University, Munich, Germany), Staffan Skerfving (University Hospital, Lund, Sweden), Giovanni Viegi, (CNR Institute of Clinical Physiology, Pisa, Italy).

\section{References}

1. Worldwide variation in prevalence of symptoms of asthma, allergic rhinoconjunctivitis, and atopic eczema: ISAAC. The International study of Asthma and allergies in childhood (ISAAC) steering committee. Lancet 1998;351:1225-32.

2. Beasley R, Crane J, Lai CK, Pearce N. Prevalence and etiology of asthma. J Allergy Clin Immunol 2000;105:S466-72.

3. Sterk PJ, Buist SA, Woolcock AJ, Marks GB, Platts-Mills TA, von Mutius E, et al. The message from the World Asthma Meeting. The Working Groups of the World Asthma Meeting, held in Barcelona, Spain, December 9-13, 1998. Eur Respir J 1999;14:1435-53.

4. Lundbäck B. Epidemiology of rhinitis and asthma. Clin Exp
Allergy 1998;28:3-10.

5. Variations in the prevalence of respiratory symptoms, selfreported asthma attacks, and use of asthma medication in the European Community Respiratory Health Survey. Eur Respir J 1996;9:687-95.

6. Hopkin JM. Mechanisms of enhanced prevalence of asthma and atopy in developed countries. Curr Opinion Immunol 1997;9:788-92.

7. Warner JO, Pohunek P, Marguet C, Roche WR, Clough JB. Issues in understanding childhood asthma. J Allergy Clin Immunol 2000;105:S473-6.

8. Meyer J, Holt D, Cherry N, McDonald JC. Sword '98: surveillance of work-related and occupational respiratory diseases in the UK. Occup Med 1999;49:485-9.

9. Mapp C. Agents, old and new, causing occupational asthma. Occup Environ Med 2001;58:354-60.

10. von Mutius E, Weiland SK, Firtzsch C, Duhme H, Keil U. Increasing prevalence of hay fever and atopy among children in Leipzig, East Germany. Lancet 1998;351:862-6.

11. Blanc PD, Toren K. How much adult asthma can be attributed to occupational factors? Am J Med 1999; 107:580-6.

12. Kogevinas M, Anto JM, Sunyer J, Tobias A, Kromhout H, Burney P. Occupational asthma in Europe and other industrialised areas: a population-based study: European Community Respiratory Health Survey Study Group. Lancet 1999;353:1750-4. [published erratum appears in Lancet 1999;354(9173):166].

13. Ihre E, Zetterström O. Increase in nonspecific bronchial responsiveness after repeated inhalations of low doses of allergen. Clin Exp Allergy 1993;23:298-305.

14. Fabbri LM, Mapp C. Bronchial hyperresponsiveness, airway inflammation and occupational asthma induced by toluene diisocyanate. Clin Exp Allergy 1991;21:42-7.

15. Heederik D. Epidemiology of occupational respiratory diseases and risk factors. In: Annesi-Maesano I, Gulsvik A, Viegi G. Respiratory epidemiology in Europe. Lausanne: European Respiratory Society, 2000:429-47. European respiratory monograph, no 15 .

16. Monso E, Magarolas R, Radon K, Danuser B, Iversen M, Weber C, et al. Respiratory symptoms in European crop farmers. Am J Respir Crit Care Med 2000;162:1246-50.

17. Jaakkola MS, Samet JM. Summary;workshop on health risks attributable to ETS exposure in the workplace. Environ Health Perspect 1999;107:823-8.

18. Almqvist C, Egmar A-C, Hedrén M, Larsson P, Lauber A, Malmberg $\mathrm{P}$ et al. The school: a risk environment for cat allergic children and a site of cat allergen transfer to homes. J Allergy Clin Immunol 1999;103:1012-7.

Reprint requests to: Dr Per Malmberg, National Institute for Working Life, SE-171 84 Stockholm, Sweden. [e-mail: per.malmberg@niwl.se] 